\title{
Penerapan Model ARIMA-ARCH untuk Meramalkan Harga Saham PT Indofood Sukses Makmur Tbk
}

\author{
Yulvia Fitri Rahmawati *; Etik Zukhronah; Hasih Pratiwi. \\ Universitas Sebelas Maret \\ Jl. Ir. Sutami No.36A, Kentingan, Surakarta \\ *yulviafitri@student.uns.ac.id
}

\begin{abstract}
The stock price is the value of the stock in the market that fluctuates from time to time. Time series data in the financial sector generally have quite high volatility which can cause heteroscedasticity problems. This study aims to model and to predict the stock price of PT Indofood Sukses Makmur Tbk using the ARIMA-ARCH model. The data used is daily stock prices from 2nd June 2020 to 15 th February 2021 as training data, while from 16th February 2021 to 1st March 2021 as testing data. ARIMA-ARCH model is a model that combines Autoregressive Integrated Moving Average (ARIMA) and Autoregressive Conditional Heteroscedasticity (ARCH), which can be used to overcome the residues of the ARIMA model which are indicated to have heteroscedasticity problems. The result showed that the model that could be used was ARIMA(1,1,2)-ARCH(1). This model can provide good forecasting result with a relatively small MAPE value of $0.515785 \%$.
\end{abstract}

Keywords : Stock Price; Heteroscedasticity; ARIMA; ARCH.

Abstrak - Harga saham adalah nilai saham di pasar yang berfluktuasi dari waktu ke waktu. Data runtun waktu di sektor keuangan umumnya memiliki volatilitas cukup tinggi yang dapat menyebabkan masalah heteroskedastisitas. Penelitian ini bertujuan untuk memodelkan dan meramalkan harga saham PT Indofood Sukses Makmur Tbk menggunakan model ARIMA-ARCH. Data yang digunakan adalah harga saham harian dari 2 Juni 2020 hingga 15 Februari 2021 sebagai data training, sedangkan dari 16 Februari 2021 hingga 1 Maret 2021 sebagai data testing. Model ARIMA-ARCH merupakan suatu model yang menggabungkan Autoregressive Integrated Moving Average (ARIMA) dan Autoregressive Conditional Heteroscedasticity (ARCH), yang dapat digunakan untuk mengatasi residu dari model ARIMA yang terindikasi memiliki masalah heteroskedastisitas. Hasil penelitian menunjukkan bahwa model yang dapat digunakan adalah ARIMA(1,1,2)-ARCH(1). Model tersebut mampu memberikan hasil peramalan yang baik dengan perolehan nilai MAPE yang relatif kecil yaitu $0,515785 \%$.

Kata Kunci : Harga Saham; Heteroskedastisitas; ARIMA; ARCH.

\section{PENDAHULUAN}

Investasi merupakan suatu kegiatan penanaman modal pada perusahaan atau proyek. Tujuan yang diharapkan dengan melakukan investasi adalah memperoleh sejumlah keuntungan di masa mendatang. Kegiatan investasi saat ini sudah menjadi salah satu sumber pendapatan dan semakin banyak dilakukan oleh masyarakat. Karena semakin banyak masyarakat yang tertarik melakukan investasi, maka perusahaan juga semakin banyak yang memanfaatkan peluang tersebut melalui penawaran saham untuk memperoleh sumber modal[1].

Kegiatan investasi saham mampu memberikan keuntungan besar bagi para pelaku investasi. Namun di samping itu, investasi saham juga berpotensi mampunyai resiko yang cukup tinggi. Pada dasarnya, mekanisme permintaan dan penawaran dapat mempengaruhi terbentuknya harga saham. Pergerakan naik dan turunnya harga saham bergantung pada kekuatan permintaan dan penawaran saham sehingga dapat berubah dari waktu ke waktu.
Nilai suatu perusahaan dapat ditunjukkan oleh harga saham perusahaan tersebut. Semakin tinggi harga saham suatu perusahaan, maka akan semakin tinggi pula nilai perusahaan tersebut di mata para investor [2]. Nilai perusahaan dapat digunakan untuk mengukur efektivitas perusahaan dan mempunyai peranan penting dalam mempengaruhi persepsi investor terhadap kinerja perusahaan. Rasa kepercayaan seorang investor kepada perusahaan akan meningkat seiring dengan tingginya nilai perusahaan[3].

Data runtun waktu pada sektor keuangan umumnya cenderung mempunyai volatilitas yang cukup tinggi [4]. Kondisi tersebut dapat mengakibatkan terjadinya masalah heteroskedastisitas atau variansi residu tidak konstan. Dalam hal ini, masih belum cukup jika peramalan hanya menggunakan model ARIMA saja, diperlukan pula model ARCH yang dapat memperhitungkan adanya masalah heteroskedastisitas yang terjadi. Adanya peramalan yang dilakukan tersebut diharapkan dapat membantu 
dalam upaya meminimalkan resiko kerugian yang kemungkinan akan dihadapi oleh perusahaan maupun investor.

PT Indofood Sukses Makmur Tbk merupakan salah satu perusahaan besar di Indonesia yang telah didirikan sejak tahun 1971 silam. Perusahaan tersebut sangat terkenal di bidang industri pengolahan makanan dan minuman dan juga telah berhasil memasarkan produknya hingga ke berbagai mancanegara. Pergerakan harga saham perusahaan tersebut cenderung mengalami naik-turun seiring berjalannya waktu, sebab pada dasarnya nilai saham di pasar akan terus berfluktuasi. Oleh karena itu, penerapan model ARIMA-ARCH untuk meramalkan harga saham PT Indofood Sukses Makmur Tbk dilakukan dalam penelitian ini.

\section{Saham}

\section{KAJIAN PUSTAKA}

Saham adalah surat berharga yang merupakan tanda kepemilikan seseorang atau badan terhadap perusahaan [7]. Bentuk saham sendiri yaitu berupa sebuah lembaran kertas yang diterbitkan oleh perusahaan yang menyatakan kepemilikan seseorang atas perusahaan tersebut. Besar penyertaan yang ditanamkan pada perusahaan nantinya akan menentukan porsi kepemilikan atas perusahaan tersebut.

\section{Data Runtun Waktu}

Data runtun waktu yaitu himpunan data yang didapatkan secara terurut sesuai urutan waktu selama beberapa jangka periode tertentu [6]. Dengan dilakukannya analisis runtun waktu bertujuan untuk menentukan pola data di waktu lampau yang sudah dihimpun sesuai urutan waktu untuk selanjutnya digunakan dalam melakukan peramalan..

\section{Kestasioneran}

Suatu data dapat disebut telah stasioner apabila data sudah tidak mengalami penurunan maupun pertumbuhan secara tajam. Dengan kata lain, secara umum data harus terlihat membentuk horizontal sepanjang sumbu waktu. Namun diperlukan untuk melakukan differencing pada data yang masih belum stasioner agar bisa menjadi stasioner. Uji Augmented Dickey-Fuller (ADF) sering dilakukan dalam mengukur kestasioneran data runtun waktu. Dalam melakukan uji ADF digunakan hipotesis yaitu [9]:

$H_{0}: \delta=1$ (data tidak bersifat stasioner)
$H_{1}: \delta<1$ (data bersifat stasioner)

Statistik uji ADF yaitu:

$$
t=\frac{\hat{\delta}-1}{S E(\hat{\delta})}
$$

Penolakan $H_{0}$ terjadi apabila $|t| \geq\left|t_{(\alpha ; n-1)}\right|$ atau jika nilai- $p<\alpha$ dengan $\alpha$ merupakan taraf signifikansi.

\section{Autoregressive Integrated Moving Average (ARIMA)}

Pertama kali George Box dan Gwilyn Jenskin mengembangkan model ARIMA pada tahun 1976. Model ini merupakan penggabungan antara model Autoregressive (AR) berorde $p$ dengan model Moving Average (MA) berorde $q$ yang mendapatkan differencing sejumlah $d$ kali. Pada dasarnya, ARIMA menghendaki terpenuhinya asumsi stationeritas, maka differencing perlu dilakukan pada data yang tidak stasioner. Persamaan model $\operatorname{ARIMA}(p, d, q)$ yaitu:

$$
\phi_{p}(B)(1-B)^{d} Z_{t}=\theta_{0}+\theta_{q}(B) \varepsilon_{t}
$$

dengan $\phi_{p}(B)=\left(1-\phi_{p} B-\ldots-\phi_{p} B^{p}\right)$ dan $\theta_{q}(B)=(1$ $\left.-\theta_{q} B-\ldots-\theta_{q} B^{q}\right)$.

\section{Autoregressive} (ARCH)

Dalam pemodelan data runtun waktu, umumnya harus memenuhi asumsi variansi residu yang bersifat konstan. Tetapi pada kenyataannya, data runtun waktu di sektor keuangan memiliki tingkat volatilitas yang cukup tinggi. Kondisi tersebut dapat mengakibatkan terjadinya masalah heteroskedastisitas. Pada 1982, Engle telah membangun model Autoregressive Conditional Heteroscedasticity (ARCH) untuk memperhitungkan keberadaan heteroskedastisitas [8]. Bentuk dari model $\mathrm{ARCH}(r)$ yaitu:

$$
\sigma_{t}^{2}=\alpha_{0}+\sum_{i=1}^{r} \alpha_{i} \varepsilon_{t-i}^{2}
$$

dengan $\alpha_{0}>0$ dan $\alpha_{i} \geq 0, i=1, \ldots, r$.

\section{ARIMA-ARCH}

Model ARIMA-ARCH merupakan suatu model yang mengkombinasikan model ARIMA dan ARCH. Residu dari model ARIMA yang memiliki masalah heteroskedastisitas atau variansi residu yang tidak konstan dapat diatasi dengan menggunakan model $\mathrm{ARCH}$. Bentuk dari model $\operatorname{ARIMA}(p, d, q)-\mathrm{ARCH}(r)$ yaitu:

$$
\phi_{p}(B)(1-B)^{d} Z_{t}=\theta_{0}+\theta_{q}(B) a_{t}
$$

dengan variansi residu yaitu:

$$
\sigma_{t}^{2}=\alpha_{0}+\sum_{i=1}^{r} \alpha_{i} a_{t-i}^{2}
$$




\section{Uji Signifikansi Parameter}

Parameter dalam model harus diuji signifikansinya, karena suatu model dapat digunakan jika semua parameternya sudah signifikan. Uji signifikansi parameter memiliki hipotesis yaitu [3]:

$H_{0}: \beta_{j}=0$ (parameter tidak signifikan)

$H_{1}: \beta_{j} \neq 0$ (parameter signifikan)

Statistik uji:

$$
t=\frac{\hat{\beta}_{j}}{S E\left(\hat{\beta}_{j}\right)}
$$

$H_{0}$ akan ditolak apabila $|t| \geq\left|t_{\left(\frac{\alpha}{2} ; n-n_{p}\right)}\right|$ atau nilai- $p$ $<\alpha$ dengan $\alpha$ merupakan taraf signifikansi.

\section{Uji Autokorelasi}

Uji autokorelasi dapat dilakukan dengan menggunakan uji Ljung-Box yang memiliki hipotesis yaitu [9]:

$H_{0}: \rho_{1}=\rho_{2}=\cdots=\rho_{m}=0 \quad$ (tidak terdapat autokorelasi pada residu)

$H_{1}$ : Setidaknya terdapat satu $\rho_{i} \neq 0$ untuk $i=1,2, \ldots$, $m$ (terdapat autokorelasi pada residu)

Statistik uji yang digunakan yaitu:

$$
Q=n(n+2) \sum_{i=1}^{m} \frac{r_{k}^{2}}{n-k}
$$

dengan $m$ adalah jumlah lag maksimum, $n$ adalah jumlah pengamatan, dan $r_{k}$ adalah koefisien autokorelasi residu pada lag ke- $k$. $H_{0}$ akan ditolak jika $Q>\chi_{(\alpha ; m)}^{2}$ atau nilai- $p<\alpha$ dengan $\alpha$ merupakan taraf signifikansi

\section{Uji Normalitas}

Uji Jarque-Bera dapat digunakan untuk mengetahui kenormalan residu [5]. Hipotesis dalam melakukan uji ini adalah:

$H_{0}$ : Residu berdistribusi normal

$H_{1}$ : Residu tidak berdistribusi normal

Statistik uji dalam uji ini adalah:

$$
J B=n\left[\frac{S^{2}}{6}+\frac{(K-3)^{2}}{24}\right]
$$

dengan $n$ adalah banyaknya pengamatan, $S$ adalah koefisien skewness, dan $K$ adalah koefisien kurtosis. $H_{0}$ akan ditolak jika $J B>\chi_{(\alpha ; 2)}^{2}$ atau nilai- $p<\alpha$ dengan $\alpha$ merupakan taraf signifikansi. Selain itu, pengujian normalitas residu juga dapat dilakukan menggunakan analisa grafik dengan melihat normal probability plot dari residu.

\section{Uji Heteroskedastisitas}

Pengujian ini bertujuan untuk mencari tahu apakah masalah heteroskedastisitas terjadi atau tidak pada residu [8]. Uji ini dapat dilakukan dengan uji ARCH-LM menggunakan hipotesis yaitu:

$H_{0}$ : Tidak terjadi masalah heteroskedastisitas pada residu

$H_{1}$ : Terjadi masalah heteroskedastisitas pada residu Statistik uji yang digunakan yaitu:

$$
L M=n R^{2}
$$

dengan $n$ adalah banyaknya data pengamatan dan $R^{2}$ adalah koefisien determinasi. $H_{0}$ akan ditolak jika $L M$ $>\chi_{(\alpha ; m)}^{2}$ atau nilai- $p<\alpha$ dengan $\alpha$ merupakan taraf signifikansi.

\section{Peramalan}

Peramalan merupakan suatu proses yang bertujuan untuk memperoleh gambaran masa depan berdasarkan informasi data pada masa lampau dan saat ini.

\section{Ukuran Akurasi}

Setelah melakukan proses peramalan, pengukuran tingkat akurasi hasil peramalan dapat menggunakan Mean Absolute Percentage Error atau yang sering disebut MAPE. Dengan semakin kecilnya nilai MAPE, kesalahan peramalannya pun akan semakin kecil. Dengan demikian, hasil peramalannya akan mendekati nilai aktual dan semakin baik. MAPE dapat dihitung dengan menggunakan rumus:

$$
M A P E=\left[\frac{1}{n} \sum_{t=1}^{n} \frac{\left|Z_{t}-\hat{Z}_{t}\right|}{Z_{t}}\right] \times 100 \%
$$

dengan $n$ adalah jumlah periode peramalan, $Z_{t}$ adalah nilai data aktual, dan $\hat{Z}_{t}$ adalah nilai peramalan.

\section{Penelitian Tedahulu}

Adapun penelitian sebelumnya telah dilakukan oleh Desvina dan Meijer pada tahun 2018 tentang pengaplikasian model ARCH pada data nilai tukar petani [1]. Hasil yang didapatkan dari adanya penelitian tersebut menyatakan bahwa model ARCH terbukti mampu mengatasi masalah heteroskedastisitas dan memberikan hasil peramalan nilai tukar petani dengan akurat dan dapat memodelkan variansi residunya.

\section{METODE PENELITIAN}

Data dalam penelitian ini menggunakan data harga penutupan saham harian PT Indofood Sukses Makmur Tbk dalam satuan rupiah yang diperoleh dari situs web www.id.investing.com. Pada penelitian ini, digunakan data training dari tanggal 2 Juni 2020 
hingga 15 Februari 2021 sebanyak 172 data untuk menentukan model. Sedangkan data testing dari tanggal 16 Februari 2021 hingga 1 Maret 2021 sebanyak 10 data digunakan untuk mengevaluasi model.

Hal pertama dalam melakukan penelitian ini adalah membuat plot data training harga saham. Kemudian dilakukan uji stasioneritas untuk memastikan terpenuhinya asumsi stasioneritas pada data tersebut, sehingga pada data yang masih belum stasioner harus memperoleh differencing dahulu agar menjadi stasioner.

Dalam pembentukan model ARIMA, tahapan awal yang perlu dilakukan adalah mengidentifikasi model untuk mengetahui model tentatif. Selanjutnya menentukan estimasi parameter model ARIMA serta menguji signifikansi parameter dalam model tersebut. Setelah diperoleh model ARIMA yang signifikan, perlu dilakukan uji diagnostik untuk memastikan telah terpenuhinya semua asumsi residu model ARIMA. Uji diagnostik tersebut meliputi uji autokorelasi, uji normalitas, serta uji heteroskedastisitas pada residu.

Jika residu model ARIMA terindikasi memiliki masalah heteroskedastisitas, maka diperlukan model ARCH yang dapat memodelkan variansi residu dari model ARIMA. Setelah itu, menentukan estimasi parameter dari model ARIMA-ARCH untuk selajutnya dapat dilakukan uji signifikansi parameter pada model tersebut. Apabila telah diperoleh model yang signfikan, langkah berikutnya adalah melakukan uji diagnostik kembali pada residu model. Selanjutnya model ARIMA-ARCH tersebut kemudian digunakan untuk melakukan peramalan. Setelah melakukan proses peramalan, kemudian untuk mengevaluasi hasil peramalan yang telah diperoleh tersebut maka dapat dengan melakukan perhitungan nilai MAPE.

\section{HASIL DAN PEMBAHASAN}

\section{Plot data}

Plot data harga saham harian dari tanggal 2 Juni 2020 sampai dengan 15 Februari 2021 dapat disajikan pada Gambar 1.

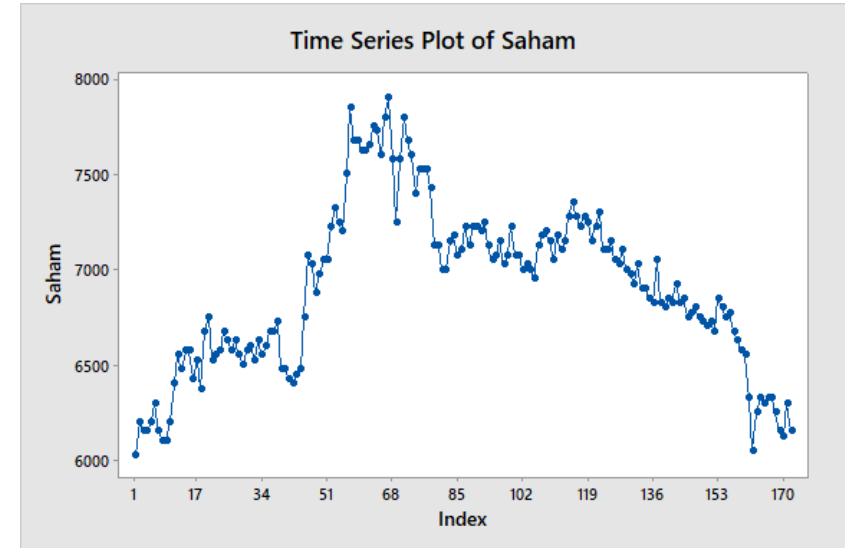

Sumber: Data diolah (2021)

Gambar 1. Plot Data Harga Saham

Dari plot data yang ditunjukkan Gambar 1 terlihat adanya pergerakan harga saham yang bersifat fluktuatif. Berdasarkan pola pada plot tersebut mengindikasikan adanya pelanggaran asumsi kestasioneran pada data, sehingga diperlukan melakukan pengujian untuk mengetahui kestasioneran data tersebut.

\section{Kestasioneran}

Uji Augmented Dickey-Fuller (ADF) perlu dilakukan untuk memastikan apakah asumsi stasioneritas data telah terpenuhi atau belum. Setelah dilakukan uji ADF dengan taraf signifikansi $\alpha=0,05$, perolehan nilai- $p$ yang didapat yaitu sebesar 0,5886 sehingga $H_{0}$ tidak ditolak sebab nilai- $p$ lebih besar daripada $\alpha=0,05$ maka mengartikan bahwa asumsi stasioneritas masih belum terpenuhi. Oleh sebab itu, differencing perlu dilakukan agar diperoleh data stasioner.

Setelah dilakukan differencing pertama $(d=1)$, menghasilkan perolehan nilai- $p$ yang lebih kecil dibandingkan $\alpha=0,05$ yakni 0,0000 artinya data telah bersifat stasioner atau $H_{0}$ ditolak. Plot data harian harga saham setelah stasioner dapat ditunjukkan pada Gambar 2.

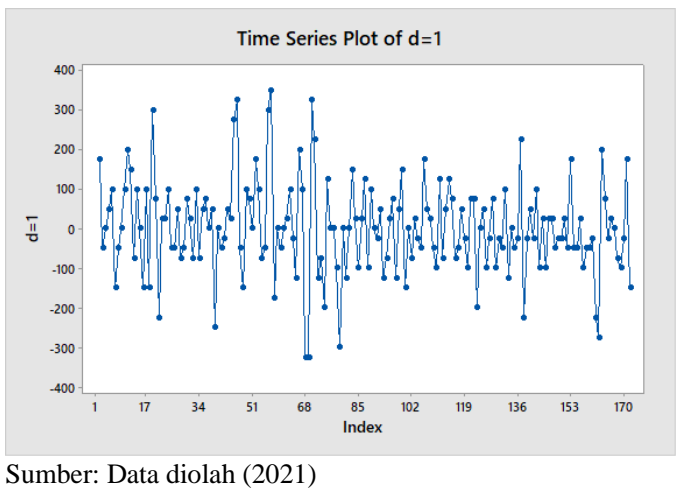

Gambar 2. Plot Data Setelah Differencing 
Dilihat dari Gambar 2 tampak data sudah stasioner. Hal ini ditandai dengan pola datanya yang cenderung terletak pada sekitar nilai rata-rata konstan.

\section{Pembentukan Model ARIMA}

Tahapan awal dalam membentuk model ARIMA yaitu melakukan identifikasi model berdasarkan plot Autocorrelation Function (ACF) yang ditunjukkan pada Gambar 3 serta Partial Autocorrelation Function (PACF) yang ditunjukkan pada Gambar 4.

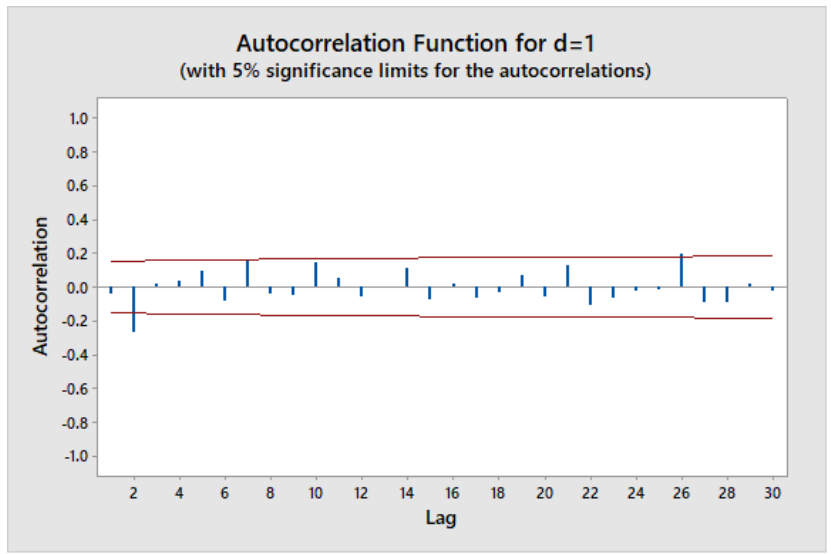

Sumber: Data diolah (2021)

Gambar 3. Plot ACF Data Setelah Differencing

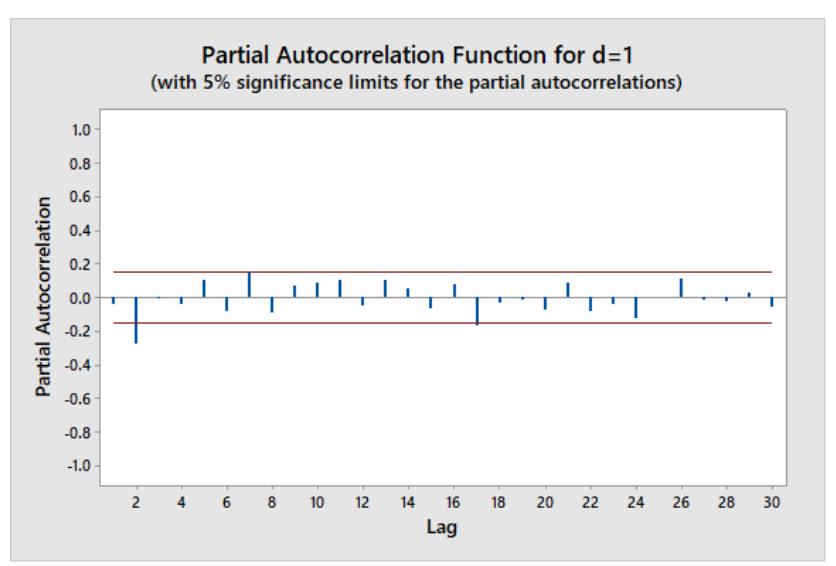

Sumber: Data diolah (2021)

Gambar 4. Plot PACF Data Setelah Differencing

Gambar 3 dan Gambar 4 menunjukkan bahwa lag ke-2 keluar dari pita konfidensi plot ACF dan PACF. Oleh karena itu, terdapat beberapa kemungkinan model ARIMA, yaitu: $\operatorname{ARIMA}(1,1,0), \operatorname{ARIMA}(0,1,1)$, $\operatorname{ARIMA}(1,1,1), \quad$ ARIMA $(2,1,0), \quad \operatorname{ARIMA}(0,1,2)$, $\operatorname{ARIMA}(2,1,1), \operatorname{ARIMA}(1,1,2)$, dan $\operatorname{ARIMA}(2,1,2)$. Dari hasil uji signifikansi parameter, hanya diperoleh satu model saja yaitu model $\operatorname{ARIMA}(1,1,2)$ karena semua parameternya sudah signifikan.

Tabel 1. Estimasi Parameter Model ARIMA(1,1,2)

\begin{tabular}{ccc}
\hline Parameter & Koefisien Parameter & Nilai- $\boldsymbol{p}$ \\
\hline AR(1) & $-0,547$ & 0,000 \\
MA(1) & $-0,554$ & 0,000 \\
MA(2) & 0,3541 & 0,000 \\
\hline Sumber: Data diolah (2021) & &
\end{tabular}

Tabel 1 menunjukkan semua parameternya mempunyai nilai- $p$ kurang dari 0,05 sehingga $\operatorname{ARIMA}(1,1,2)$ diketahui sebagai model yang signifikan. Setelah diperoleh model ARIMA yang signifikan, berikutnya uji diagnostik dilakukan dengan uji autokorelasi, uji normalitas, serta uji heteroskedastisitas pada residu model tersebut. Pada uji autokorelasi, diperoleh nilai-p untuk semua lag-nya lebih besar daripada 0,05. Berdasarkan hasil dari uji tersebut dapat mengartikan jika tidak ada autokorelasi yang terjadi pada residu model. Selain itu, hasil dari uji kenormalan residu menunjukkan perolehan nilai- $p$ lebih besar daripada 0,05 dimana itu artinya residu telah berdistribusi normal. Sedangkan nilai- $p$ dari hasil uji heteroskedastisitas bernilai kurang dari 0,05. Dimana hal ini mengindikasikan adanya kasus heteroskedastisitas pada residu model tersebut. Meskipun asumsi non autokorelasi dan berdistribusi normal telah terpenuhi, namun residu model masih memiliki masalah heteroskedastisitas.

\section{Pembentukan Model ARIMA-ARCH}

Setelah dilakukan pengujian, dapat diketahui bahwa model ARIMA terindikasi memiliki masalah heteroskedastisitas pada residu model. Oleh karena itu, dalam kondisi variansi residu yang tidak konstan dapat digunakan model ARIMA-ARCH untuk mengatasinya. Model yang digunakan adalah model $\operatorname{ARIMA}(1,1,2)-\operatorname{ARCH}(1)$.

Tabel 2. Estimasi Parameter Model ARIMA(1,1,2)$\mathrm{ARCH}(1)$

\begin{tabular}{ccc}
\hline Parameter & Koefisien Parameter & Nilai- $\boldsymbol{p}$ \\
\hline AR(1) & $-0,658836$ & 0,0000 \\
MA(1) & 0,540230 & 0,0000 \\
MA(2) & $-0,374189$ & 0,0000 \\
C & 7955,128 & 0,0000 \\
ARCH(1) & 0,378559 & 0,0082 \\
\hline Sumber: Data diolah (2021) & &
\end{tabular}

Tabel 2 menunjukkan semua parameternya memiliki nilai- $p$ lebih kecil daripada 0,05 sehingga model ARIMA(1,1,2)-ARCH(1) diketahui sebagai model yang signifikan. Setelah mengetahui bahwa model ARIMA-ARCH telah signifikan, tahap berikutnya adalah melakukan uji diagnostik kembali pada residu dari model tersebut untuk menguji kelayakan model. Berdasarkan hasil uji autokorelasi 
yang telah dilakukan, menyatakan bahwa tidak terdapat autokorelasi residu dikarenakan nilai- $p$ pada semua lag-nya lebih besar daripada 0,05 . Selain itu, hasil dari uji kenormalan dan uji heteroskedastisitas memberikan nilai- $p$ lebih besar dari 0,05 pada kedua uji tersebut. Dengan demikian, residu model ARIMAARCH berdistribusi normal dan sudah tidak memiliki masalah heteroskedastisitas. Hal tersebut sesuai dengan hasil penelitian terdahulu yang telah dilakukan oleh Desvina dan Meijer pada tahun 2018 yang menyatakan bahwa model ARCH terbukti mampu mengatasi masalah heteroskedastisitas pada residu.

Berdasarkan hasil uji diagnostik yang telah diperoleh, maka model ARIMA(1,1,2)-ARCH(1) dapat dinyatakan layak untuk digunakan meramalkan harga saham dengan persamaan:

$$
\begin{aligned}
Z_{t}=0, & 341164 Z_{t-1}-0,658836 Z_{t-2} \\
& -0,54023 a_{t-1}+0,374189 a_{t-2}
\end{aligned}
$$

dan variansi residunya yaitu:

$$
\sigma_{t}^{2}=7955,128+0,378559 a_{t-1}^{2}
$$

\section{Peramalan}

Model ARIMA(1,1,2)-ARCH(1) selanjutnya digunakan untuk melakukan peramalan harga saham dari tanggal 16 Februari 2021 hingga 1 Maret 2021. Plot hasil peramalan tersebut dapat ditunjukkan pada Gambar 5.

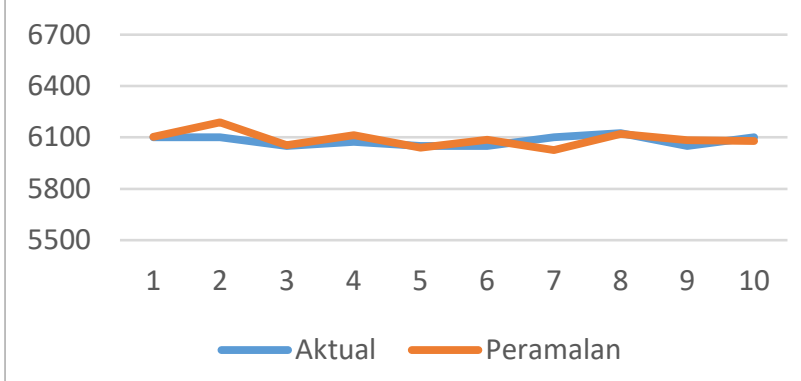

Sumber: Data diolah (2021)

Gambar 5. Plot Perbandingan Data Harga Saham Aktual dengan Peramalan

Gambar 5 menunjukkan perbandingan data aktual dengan hasil peramalan, dimana terlihat bahwa hasil peramalan sudah mendekati nilai data aktual dan cukup akurat. Hasil peramalan dengan model tersebut juga memberikan nilai MAPE yang relatif kecil yaitu $0,515785 \%$. Dengan demikian, model ARIMA $(1,1,2)$ $\mathrm{ARCH}(1)$ telah representatif untuk melakukan peramalan harga saham..

\section{KESIMPULAN DAN SARAN}

\section{Kesimpulan}

Dari uraian hasil dan pembahasan pada penelitian ini, dapat diambil kesimpulan bahwa $\operatorname{ARIMA}(1,1,2)$ ARCH(1) merupakan model yang dapat digunakan untuk meramalkan harga saham. Peramalan dengan menggunakan model tersebut dapat memberikan hasil peramalan yang cukup akurat terhadap harga saham PT Indofood Sukses Makmur Tbk dengan nilai MAPE yang diperoleh relatif kecil yaitu $0,515785 \%$.

\section{Saran}

Dalam penelitian ini, digunakan model ARCH untuk memodelkan variansi residu. Bagi penelitian berikutnya, alangkah baiknya apabila dapat dikembangkan dan dibandingkan dengan model lainnya agar dapat memperoleh hasil peramalan yang lebih akurat.

\section{REFERENSI}

[1] A. P. Desvina dan I. O. Meijer, "Penerapan Model ARCH/GARCH untuk Peramalan Nilai Tukar Petani”, Jurnal Sains Matematika dan Statistika, Vol. 4, No. 1, Hal. 43-54, 2018.

[2] B. I. Wijaya dan I. B. P. Sedana, "Pengaruh Profitabilitas Terhadap Nilai Perusahaan (Kebijakan Dividen dan Kesempatan Investasi Sebagai Variabel Mediasi)", EJurnal Manajemen Universitas Udayana, Vol. 6, No. 12, Hal. 4477-4500, 2015.

[3] D. C. Montgomery, C. L. Jennings, and M. Kulahci, Introduction to Time Series Analysis and Forecasting, $2^{\text {nd }}$ ed., New Jersey: John Wiley and Sons, 2015.

[4] D. H. Ratnasari, Tarno, dan H. Yasin, "Peramalan Volatilitas Menggunakan Model Generalized Autoregressive Conditional Heteroscedasticity in Mean (GARCH-M)", Jurnal Gaussian, Vol. 3, No. 4, Hal. 655-662, 2014.

[5] D. N. Gujarati, Basic Econometrics, $4^{\text {th }}$ ed., New York: McGraw-Hill, 2003.

[6] D. Rosadi, Pengantar Analisa Runtun Waktu, Yogyakarta: Fakultas Matematika dan Ilmu Pengetahuan Alam, Universitas Gadjah Mada, 2006.

[7] I. Oei, Kiat Investasi Valas, Emas, Saham, Jakarta: PT Gramedia Pustaka Utama, 2009.

[8] R. F. Engle, "Autoregressive Conditional Heteroscedasticity with Estimation of the Variance of United Kingdom Inflation", Journal Econometrica, Vol. 50, No.4, pp. 987-1007, 1982. 
[9] R. S. Tsay, Analysis of Financial Time Series, New Jersey: John Wiley and Sons, 2005.

Business Innovation and Entrepreneurship Journal (BIEJ) is published under licensed of a CC BY-SA Creative Commons Attribution-ShareAlike 4.0 International License. 